\title{
Respiration predicted from an Enzyme Kinetic Model and the Metabolic Theory of Ecology in two species of marine bacteria
}

\author{
Borja Aguiar-González ${ }^{\mathrm{a}}$, Ted T. Packard ${ }^{\mathrm{b}, \mathrm{c}, \mathrm{e}}$, Elisa Berdalet ${ }^{\mathrm{c}}$, \\ Sylvie Roy ${ }^{\mathrm{d}}$, May Gómez ${ }^{\mathrm{b}}$ \\ ${ }^{a}$ Departamento de Física, Facultad de Ciencias del Mar, Universidad de Las \\ Palmas de Gran Canaria, E- 35017 Las Palmas de Gran Canaria, Spain \\ ${ }^{b}$ Institute of Oceanography and Global Change, Biological Oceanography \\ Group, Universidad Las Palmas de Gran Canaria, Las Palmas de Gran \\ Canaria, Spain \\ ${ }^{c}$ Institut de Ciències del Mar (CSIC), Passeig Marítim de la Barceloneta \\ 37-49, 08003 Barcelona, Spain \\ ${ }^{d} 3579 A$ Delson drive, P.O. Box 348, Navan, Ontario K4B 1J5, Canada \\ ${ }^{e}$ Bigelow Laboratory for Ocean Sciences, W. Boothbay Harbor, ME \\ $04538, U S A$
}

Abstract

Respiratory oxygen consumption is the result of a cell's biochemistry. It is caused by enzymatic activity of the respiratory electron transfer system (ETS). However, in spite of this understanding, respiration models continue to be based on allometric equations relating respiration to body size, body surface, or biomass. The Metabolic Theory of Ecology (MTE) is a current example. It is based on Kleiber's Law relating respiration $(R)$ and biomass $(M)$ in the form, $R=C M^{\frac{3}{4}} \mathrm{e}^{\frac{-E_{a}}{k T}}$, where $C$ is a constant, $E_{a}$ is the Arrhenius activation energy, $k$ is the Boltzmann constant for an atom or molecule, and $\mathrm{T}$ is the temperature in Kelvin. This law holds because biomass packages the ETS. In contrast, we bypass biomass and model respiration directly from its causal relationship with the ETS activity, $R=\mathrm{f}$ (ETS). We use a biochemical

\footnotetext{
*Corresponding author. Tel.: +34 9284529 05; fax: +34 928452922

Prepeint gubmitted to Elsevier.aiar102@doctorandos.ulpgc.es

September 20, 2011

(Borja Aguiar-González)
} 
Enzyme Kinetic Model (EKM) of respiratory oxygen consumption based on the substrate control of the ETS. It postulates that the upper limit of $R$ is set by the maximum velocity, $V_{\max }$, of complex I of the ETS and the temperature, and that the substrate availability, $S$, modulates $R$ between zero and this upper limit. Kinetics of this thermal-substrate regulation are described by the Arrhenius and Michaelis-Menten equations. The EKM equation takes the form $R=\frac{E T S[S] e^{\frac{-E_{q}}{R_{g} T}}}{K+[S]}$ where $R_{g}$ is the molar gas constant and $K$ is the Michaelis-Menten constant.

Here, we apply the EKM and the MTE to predict a respiration timeprofile throughout the exponential, steady state, and nutrient-limited phases of the marine bacteria Pseudomonas nautica and Vibrio natriegens in acetatebased cultures. Both models were tested by comparing their output with the measured $R_{\mathrm{O}_{2}}$ time-profile. The MTE predicted respiration accurately only in the exponential growth phase, but not during the nutrient limitation part of the stationary phase. In contrast, the EKM worked well throughout both physiological phases as long as the modelled substrates fall with the declining carbon source. Results support the theoretical bases of the EKM. We conclude that the EKM holds promise for predicting respiration at the different physiological states and time-scales important to microbiological studies.

Keywords: ETS, modeling respiration, MTE, Oxygen consumption

\section{Introduction}

First principles-based models of physiological processes are rare. For respiration we have statistically based allometric equations relating respiration 
to body size, body surface, or biomass (Weibel, 2002; Brown et al., 2004; Allen and Gillooly, 2007). However, we have few models relating respiration to the fundamental chemical principles and processes that control it. Equations for respiration based on biochemical principles and properties such as enzyme activities and substrate concentrations are not unreasonably difficult to conceive, but have rarely been formulated as they have been for nitrogen uptake and photosynthesis (Packard et al., 1971; Farquhar et al., 1980). Such models would provide a means for calculating physiological rates when direct measurements are impractical. Here we present a biochemical model of respiratory oxygen consumption based on the substrate control of the respiratory electron transport system. This model follows the equations designed to calculate phytoplankton nitrate uptake (Packard et al., 1971), and bacterial respiration (Packard et al., 1996a,b; Roy and Packard, 2001). They are conceptually similar to Farquhar's photosynthetic model (Farquhar et al., 1980).

The derivation of these equations is based on the assumptions that (1) respiration is the direct result of intracellular activity of the electron transport system (ETS) following a definable stoichiometry; (2) regulation of the ETS, and hence respiration $\left(R_{O_{2}}\right)$ at the physiological level, is controlled by the NADH Dehydrogenase (EC 1.6.99.3.); and NADPH transferase (EC 1.6.1.1.) at the entrance to the ETS; and (3) that the reactions of these enzymes obey the rules of enzyme kinetics.

The Metabolic Theory of Ecology (MTE) provides an alternative model of respiration. Since the middle 90's articles proposing the MTE as a new unified theory for biology (Whitfield, 2005, 2006), based on the allometric 
equation of Kleiber (1932), have appeared in key journals (Brown et al., 2000, 2004; Brown and West, 2000; Enquist et al., 1998, 2000; West et al., 1997, 2000, 2001). The proponents argue convincingly that anabolic and catabolic metabolism are determined by biomass, temperature, and the flux of elemental materials through an organism. They find parallel fractal scaling in animal and plant distribution networks and circulatory systems as well as similar thermodynamics and metabolic kinetics to explain the widespread allometry with biomass. The MTE argues that respiration in all organisms, including bacteria, can be calculated from biomass $(\mathrm{M})$, temperature $(\mathrm{T})$, and a stoichiometric factor $(\mathrm{C})$ that controls the uptake of minerals and nutrients (Brown et al., 2004). The MTE algorithm is:

$$
R=C M^{\frac{3}{4}} e^{\frac{-E_{a}}{k T}}
$$

The biomass $(\mathrm{M})$, with an exponent $b=\frac{3}{4}$, is the core of Kleiber's law, $R=a M^{b}$ (Kleiber, 1932, 1961; Whitfield, 2006), where $a$ is a constant. In the MTE this constant, $a$, is folded into the MTE constant, $C$. In Kleiber's law when $M^{b}=1, a=R$ and thus the units of $a$ and $R$ are the same. Kleiber's Law holds over a range of $10^{20}$ (Hochachka and Somero, 2002; Whitfield, 2006). The temperature dependency is based on the Boltzmann factor, $e^{\frac{-E a}{k T}}$, where $E_{a}$ is the Arrhenius energy of activation (for respiration, $E_{a} \approx 0.65 \mathrm{eV}$ (Allen and Gillooly, 2007)), $k$ is the Boltzmann constant for an atom or molecule $\left(0.33 \times 10^{-23}\right.$ cal $\mathrm{K}^{-1}$ or $8.62 \times 10^{-5} \mathrm{eV} \mathrm{K}^{-1}$ (Allen and Gillooly, 2007)), and $\mathrm{T}$ is the temperature in Kelvin. For the stoichiometric factor, or nutrient availability, the MTE uses the constant, $C$ (or $\mathrm{b}_{0}$, (Gillooly et al., 2006)). This MTE has been applied to secondary production, respiration 
(Gillooly et al., 2001), growth, and developmental time (Gillooly et al., 2002, 2003), etc. in both plants and animals.

The Enzyme Kinetic Model (EKM) argues that each metabolic process is controlled by the maximum velocity $\left(V_{\max }\right)$ of the enzyme reaction that controls the process, the temperature $(T)$, and the substrate availability $(S)$. Focused on respiration $\left(R_{1}\right)$, at temperature $T_{1}$, the EKM equation takes the form:

$$
R_{1}=\frac{E T S_{0}[S] e^{\frac{-E_{a}}{R_{g}\left(T_{1}-T_{0}\right)}}}{K+[S]}
$$

$E T S_{0}$ is the potential respiration rate (in the same units as the physiological rate, $R_{1}$ ) but measured at another temperature, $T_{0}$. ET $S_{0}$ is also the in vitro activity of the respiratory electron transport system, its $V_{\max }$ (sensu Michaelis-Menten). The expression $e^{\frac{-E_{a}}{R_{g}\left(T_{1}-T_{0}\right)}}$ is from the Arrhenius Equation where $E_{a}$ is the Arrhenius energy of activation $\left(\approx 15 \mathrm{Kcal} \mathrm{mol}^{-1} \mathrm{~K}^{-1}\right)$, $R_{g}$ is the gas constant $\left(1.987 \mathrm{cal} \mathrm{mol}^{-1}\right)$, and $T_{0}$ and $T_{1}$ are in Kelvin for the measured potential rate $\left(\Phi\right.$ or $\left.E T S_{0}\right)$ and the predicted rate $\left(R_{1}\right)$, respectively. It is important to note here that the Arrhenius Equation uses molar units whereas the Boltzmann Factor in the MTE uses atomic units. $S$ is the reactant (substrate) of the enzyme reaction, controlling respiration. $K$, for a single-reactant reaction $(S \rightarrow P$, where $P$ is the product of the reaction), is the Michaelis-Menten constant $\left(K_{m}\right)$.

In the case of a bisubstrate reaction, $\left(S_{1}+S_{2} \rightarrow P_{1}+P_{2}\right), S$ becomes $\left[S_{1} S_{2}\right]$ and $K$ becomes

$$
K_{\beta}=K_{S_{1}} K_{i a}+K_{S_{2}}\left[S_{1}\right]+K_{S_{1}}\left[S_{2}\right]
$$


where $K_{i a}$ is the dissociation constant for the enzyme- $S_{2}$ complex (Packard et al., 1996a,b, 2004). Note that $A$, the frequency factor in the Arrhenius equation is eliminated algebraically because $A$ is normally a constant for each reaction. In the case of physiological processes (respiration, photosynthesis, nitrogen fixation, etc.) we are assuming that $A$ is a constant. Accordingly, $A$ does not appear in Eq. (2). Furthermore if $T_{0}$ and $T_{1}$ are equal, as in this paper, then $e^{\frac{-E_{a}}{R_{g}\left(T_{1}-T_{0}\right)}}$ becomes 1 and Eq. (2) simplifies to:

$$
R_{0}=\frac{E T S_{0}[S]}{K+[S]}
$$

Note also the similarity between $e^{\frac{-E_{a}}{R_{g}\left(T_{1}-T_{0}\right)}}$, in Eq. (2), and $e^{\frac{-E a}{k T}}$, in Eq. (1). Both are derived from Maxwell's work in the 1850s and Boltzman's work in the 1860s, but the application to chemical rates was explained by Arrhenius in 1889 and the application to biological rates was again the work of Arrhenius around the turn of the century (Arrhenius, 1889, 1915). Boltzmann explained the distribution of molecular velocities and from that derived the perfect gas law. He did not explain the effect of temperature on chemical or biological reactions. That was entirely the work of Svant Arrhenius. Accordingly, an important difference between the temperature functions in the EKM and the MTE is the use of $R_{g}$ (from Arrhenius) in EKM's Eq. (2) and $k$ (from Boltzmann) in the MTE's Eq. (1). Numerically, with $k$ in atomic units, the difference is enormous because $k=\frac{R_{g}}{N}$ where $N=$ Avogadro's number, $6.022 \times 10^{23}$ atoms $\mathrm{mol}^{-1}$. If $k$ is in electron-volts, it incorporates units that biologists, chemists, and biochemists rarely use and even Richard Feynman, the Nobel laureate physicist, argued against using it in the physics community (Feynman, 1998). Feynman thought it useful in 
the atomic physics community, but not outside. For 100 years the biologicalchemical community has been measuring and using energy of activations, gas constants, and the Arrhenius equation based on molar units, so a sudden switch to electron-volt units is a major and unnecessary change.

The predictive capability of the EKM for respiratory $\mathrm{CO}_{2}$ production rates has been demonstrated in pyruvate-based cultures of the marine bacterium, Pseudomonas nautica (Roy and Packard, 2001). In that experiment, measurements of isocitrate dehydrogenase activity, provided a proxy for potential respiratory $\mathrm{CO}_{2}$ production. For respiratory oxygen consumption $\left(R_{\mathrm{O}_{2}}\right)$, this model can predict rates in P. nautica from measurements of ETS, kinetic constants from the literature, and modelled time courses of the two main ETS electron donors (reactants), NADH and NADPH (Packard et al., 1996a). These reactants are represented by $S_{1}$ and $S_{2}$ in Eq. (3). Here we show in a feasibility study that this model (Eq. (5)) can be used to predict $R_{\mathrm{O}_{2}}$ in a culture grown on an entirely different carbon source.

$$
R_{0}=\frac{E T S_{0}\left[S_{1} S_{2}\right]}{K_{S_{1}} K_{i a}+K_{S_{2}}\left[S_{1}\right]+K_{S_{1}}\left[S_{2}\right]+\left[S_{1} S_{2}\right]}
$$

The model works for an acetate-based, temperature-controlled culture of Pseudomonas nautica as well as for an acetate-based culture of another marine bacteria, Vibrio natriegens. The laboratory experiments show timeprofiles of $R_{\mathrm{O}_{2}}$ and in vitro activity of the ETS throughout the exponential and stationary phases of both marine bacteria, Pseudomonas nautica and Vibrio natriegens. It demonstrates the difference in the relationships between the ETS and $R_{\mathrm{O}_{2}}$ in the exponential and stationary phases of the bacteria cultures. Finally it shows how respiratory control is achieved by substrate 
modulation of the ETS. The model presented here demonstrates this substrate control. It is based on the concept that the concentration of the ETS substrates (NADH and NADPH) can be calculated from the concentration of the carbon source (acetate) in the culture medium and the biomass of the population. In addition, it is based on the assumption of bisubstrate kinetic control of the ETS activity in the bacteria populations. The model is tested by comparing its output, the respiration time-profile, with the measured $R_{O_{2}}$ time-profile in three experiments. Furthermore it is compared with the respiration time-profile predicted by the MTE. We find that the MTE is not useful for predicting bacterial respiration beyond the exponential phase of growth. The EKM, on the other hand, predicts respiration in both the exponential and the stationary phases.

\section{Material and Methods}

\subsection{Bacterial cultures}

Pseudomonas nautica (strain 617 from Dr. P Bonin, Université de la Méditerranée, Marseille, France) and Vibrio natriegens (ATCC 33788) were adapted to the acetate media for at least 15 generations prior to the experiments. Exponential or early stationary phase cultures were used to inoculate experiments. Cultures were continually shaken orbitally at $100 \mathrm{rpm}$ at $22^{\circ} \mathrm{C}$. Growth was monitored spectrophotometrically at $550 \mathrm{~nm}$ (OD550). Reagents for the culture media were obtained from Sigma. Pseudomonas nautica was cultured according to Packard et al. (1996a). The medium for $V$. natriegens was developed from the media of Niven et al. (1977); Baumann 
and Baumann (1981); King and Berman (1984); Nissen et al. (1987) after experiments in the laboratory established the optimal growth conditions. It contained: $400 \mathrm{mM} \mathrm{NaCl}, 10 \mathrm{mM} \mathrm{MgS0}{ }_{4} 7 \mathrm{H}_{2} 0,10 \mathrm{mM} \mathrm{CaCl} 2 \mathrm{H}_{2} 0$, $10 \mathrm{mM} \mathrm{KCl}, 25 \mathrm{mM} \mathrm{NH}_{4} \mathrm{Cl}, 0.33 \mathrm{mM}$ phosphate buffer, $0.01 \mathrm{mM} \mathrm{FeS}_{4} 7 \mathrm{H}_{2} 0$, and $30 \mathrm{mM}$ sodium acetate. All components (except $\mathrm{FeSO}_{4} \quad 7 \mathrm{H}_{2} 0$ and the phosphate buffer) were dissolved in $0.22 \mu \mathrm{m}$ filtered deionized water. The $\mathrm{pH}$ was adjusted to 7.5 with $1 \mathrm{~N} \mathrm{NaOH}$. The solution was filtered through a GF/F glass fiber filter to remove particles, and autoclaved for $45 \mathrm{~min}$. at $121^{\circ} \mathrm{C}$. To avoid precipitate formation during autoclaving, the phosphate buffer (0.67 M, pH 7.5) and $\mathrm{FeS0}_{4} 7 \mathrm{H}_{2} 0$ solution $(0.1 \mathrm{mM})$ were prepared separately. The phosphate buffer was autoclaved, but the iron sulphate solution was sterilized by filtration through $0.22 \mu \mathrm{m}$ acrodiscs. Both solutions were kept frozen and added to the culture medium on the day of use.

The basic experimental design was a time-course. Bacteria cultures were grown in 25 cotton-plugged $500 \mathrm{ml}$ Erlenmeyer flasks containing $100 \mathrm{ml}$ of media. Initial OD550 after inoculation was 0.1. At about $2 \mathrm{hr}$ intervals, 2 flasks were chosen randomly, $25 \mathrm{ml}$ of culture were transferred to the Oxymax flasks, and the respiration was measured. Afterwards, the corresponding Erlenmeyer flasks were sampled for OD550, protein, ETS activity and acetate (in duplicate).

Respiration was measured in a Micro-Oxymax respirometer (Columbus Instruments International Corporation, Columbus, OH, USA) by measuring $\mathrm{O}_{2}$ changes in the head space of the experimental flasks with an oxygen detector based on the principle of an $\mathrm{PbO}_{2}$ fuel cell. The respirometer featured a multiple sample chamber (for up to 20 channels), a reference chamber, and 
a computerized data acquisition and analysis system. A measurement was accomplished in 30 min. Aerobic conditions were assured because the MicroOxymax replenished the head-space air when $\mathrm{O}_{2}$ levels fell below 19.3\%. Respiration is reported as $\mu \mathrm{mol} \mathrm{O}_{2} \mathrm{~min}^{-1} \mathrm{l}^{-1}$ (Fig. 1). The oxygen detector was calibrated with high precision gas standards. Each $R_{O_{2}}$ measurement represents the mean of duplicate analyses. The range of the duplicates was $10.0 \%$ of the mean (S.D. $9.4 \%, \mathrm{n}=20$ ).

For the acetate analysis 5 to $10 \mathrm{ml}$ of culture were centrifuged at $10000 \times \mathrm{g}$ for $15 \mathrm{~min}$ at $4^{\circ} \mathrm{C}$, the supernatant fluid was collected in an acid-rinsed Corex tube, and stored in liquid nitrogen. Later, samples were thawed and adjusted to $\mathrm{pH} 2$ by adding $3 \mu \mathrm{l}$ of concentrated phosphoric acid. Acetate was detected in its acid form by high performance liquid chromatography (HPLC) system consisting of 2 pumps (Perkin-Elmer, Norwalk, CT, USA; Series 3B), a $20 \mu \mathrm{l}$ sample loop injector (Rheodyne, model 7125), a standard $4.6 \mathrm{~mm}$ I.D. reverse-phase CI8 column (Supelcosil LC 18, d, $=3$ pm), a precolumn (Supelcosil LC 18), and a UV-VIS variable wavelength detector (PerkinElmer LC-85 and the autocontrol module). The absorbance of acetate was detected at $210 \mathrm{~nm}$. Sodium acetate (Sigma, more than 99\% pure) served as the standard. Mobile phase was prepared using HPLC grade phosphoric acid and deionized water. All chromatographic measurements were carried out at $0.7 \mathrm{ml} \mathrm{min}^{-1}$ using $0.05 \mathrm{M}$ phosphoric acid as the mobile phase.

For the ETS activity measurements, 5 to $10 \mathrm{ml}$ of culture (depending on the biomass) were centrifuged at $10000 \times \mathrm{g}$ for $15 \mathrm{~min}$ at $4^{\circ} \mathrm{C}$. The pellets were stored in liquid nitrogen. Later they were resuspended in $2 \mathrm{ml}$ of the homogenizing buffer at 0 to $4^{\circ} \mathrm{C}$, and measured kinetically for ETS activity 
with a modification of the Packard and Williams (1981) method. Details are given in Packard and Christensen (2004). Results are converted from ETS units of $\mu$ mol $\mathrm{e}^{-} \min ^{-1} \mathrm{l}^{-1}$ to potential respiration units in $\mu \mathrm{mol} \mathrm{O}_{2} \mathrm{~min}^{-1} \mathrm{l}^{-1}$ of culture by dividing by $4\left(4 \mathrm{e}^{-}+4 \mathrm{H}^{+}+\mathrm{O}_{2} \rightarrow 2 \mathrm{H}_{2} \mathrm{O}\right)$.

For the protein analysis, pellet samples were taken, frozen, and stored as in the ETS analysis. The pellets were later resuspended in 2 to $4 \mathrm{ml} 1 \mathrm{~N} \mathrm{NaOH}$ $\left(\right.$ at $22^{\circ} \mathrm{C}$ ) and mixed well. Protein analysis was performed on a $0.5 \mathrm{ml}$ sample, using the method of Lowry et al. (1951). The homogenates were diluted if the absorbance at $750 \mathrm{~nm}$ exceeded 0.4, and analysed again. Bovine Serum Albumin (BSA) from Sigma Chemical Company was used as a standard. Measurements were made in duplicate. Their range around the average of these duplicates decreased from $14 \%$ during stationary (after $15 \mathrm{hr}$ ) to $2 \%$ during exponential growth. The mean of these ranges averaged $4.1 \%$.

All measured time-courses of the culture biomass (protein), carbon source (acetate), potential respiration (in vitro ETS activity, (ETS)) and respiration presented here are listed in Tables 1, 2 and 3. The NADH and NADPH concentrations were calculated from the acetate and the protein as in Packard et al. (1996a), and as explained in the following section.

\subsection{Respiration model}

The conceptual idea of the model was originally developed from observations of declining respiration soon after pyruvate declined in a pyruvatelimited batch culture of Pseudomonas nautica (Packard et al., 1996a). Here, one can see a similar situation with acetate. In Fig. 1 the time course of $R_{O_{2}}$ is characterized by low values of bacteria respiration after 20 hours during acetate limitation (stationary phase) at constant temperature. This suggests 
that low levels of pyridine nucleotides (as ETS substrates), caused by low levels of acetate, are throttling down the in vivo ETS activity from its $V_{\max }$ to a much lower rate, its actual respiration rate. Based on the observation that the respiration falls in parallel with the falling levels of acetate, one can intuit that respiration can be described, mathematically, by an enzyme kinetic model where substrate-dependent enzyme reactions that control the ETS activity play a key role (Eq. (6)). The basis of this EKM has been explained in the Introduction here and in Packard et al. (1996a); Roy and Packard (2001); Packard et al. (2004); Packard and Gómez (2008).

Here, this type of model has been applied to temperature-controlled cultures of $P$. nautica and $V$. natriegens to test its ability to predict respiratory oxygen consumption $\left(R_{m}\right)$ in both the exponentially growing phase and the nutrient-limited stationary phase. The model is based on the following equations:

$$
R_{m}=\frac{E T S[N A D H][N A D P H]}{K_{\beta}+[N A D H][N A D P H]}
$$

where

$$
K_{\beta}=K_{N A D H} K_{i a}+K_{N A D P H}[N A D H]+K_{N A D H}[N A D P H]
$$

This is the equation for a bisubstrate enzyme controlled reaction (Segel, 1993). The concentration of the ETS substrates (NADH and NADPH) were modelled from the cell protein and the acetate concentration in the culture medium, both of the previous hour. Mathematically this means that the value of each of the pyridine nucleotides at any time was calculated from the 

over the previous sampling period.

$$
N A D H=\delta P+\omega M
$$

$$
N A D P H=\lambda P+\eta M
$$

time-averaged values of acetate $(P)$ and cell protein $(M)$ (Eqs. (8) and (9))

This use of a lag function in the calculations is an attempt to incorporate the role of cell history in determining metabolism (Roy and Packard, 2001). Accordingly, the intracellular NADP and NADPH time profiles were modelled as functions of the mean extracellular $P$ and $M$ (Eqs. (8) and (9)) during the previous intersampling period. The calculations of these midpoint values are shown in Tables 1,2 and 3. All the equations used in the EKM are summarized in Table 4.

To evaluate the models, $R_{O_{2}}$ for each experiment (Fig. 1) was modelled using the MTE and the EKM and contrasted with the measured time-profile of respiration. This way, each model's efficiency in reproducing the bacterial respiration time-course in the two different physiological states would be seen clearly. To make these calculations for a constant temperature with the MTE one needs to reduce Eq. (1) to:

$$
R=C M^{b}
$$

The data for $M$ are listed in Tables 1, 2 and 3 .

Note that, at a constant temperature, the Boltzmann factor in Eq. (1) is no longer involved. The values $C$ and $b$, in Eq. (10), represent the stoichiometric factor or 'normalization constant' (Brown et al., 2004; Allen and 
Gillooly, 2007) and Kleiber's Law scaling factor, respectively. For the value of $b$, one can use $3 / 4$ from Kleiber's Law or one can determine it from the experimental data. Here, we have used the data from the exponential growth phase of the culture with P. nautica (Experiment A) (Table 1) and the culture with $V$. natriegens (Experiment B) (Table 2), and plotted $\log _{10} R$ versus $\log _{10} M$. By this analysis $C$ is equal to the antilogarithm of the intercept and $b$ is the slope of the regression line. This procedure insures that the MTE can make its best prediction; if all the data had been used there would have been no useful relationship between $R$ and $M$ and the MTE prediction would have been worse. Accordingly, by using only the exponential phase data to calculate those expressions, the $\mathrm{r}^{2}$ was 0.986 and 0.999 for Experiment $\mathrm{A}$ and Experiment B, respectively. Because Experiment $\mathrm{C}$ was a long-term study it had only three data points within the exponential growth phase (Table 3). Using these three points would not have yielded a reliable algorithm. Consequently, we have used the expression from Experiment B (Eq. 12), which by having seven data points for the same species and carbon source yielded a more robust equation. The resulting MTE algorithms for the three experiments at constant temperature became:

$$
\begin{gathered}
R=1.0359 M^{0.7963} \quad(\text { Experiment } A) \\
R=0.7671 M^{0.7795} \quad(\text { Experiment } B \text { and } C)
\end{gathered}
$$

The comparable calculation with the EKM at a constant temperature was made with Eq. (6) and Eq. (7). 


\subsection{Modeling computation}

The initial calculations for this acetate-based model used the pyruvatebased model of the marine bacterium P. nautica (Packard et al., 1996a) for all three experiments. Accordingly, for the ETS-substrates, NADPH and NADH, we used the same algorithms (Eqs. (8) and (9)) as in Packard et al. (1996a) with the same parameters (Table 5, Column 1). In all cases the input consisted of smoothed time-course data following the Loess method (Hutcheson, 1995). In optimizing the model for experiments with Vibrio natriegens, we changed the parameters $\lambda$ and $\delta$. In VnAc1105, the parameters $\lambda$ and $\delta$ were reduced by a third using a factor of 0.3294 (Table 5 , Column 2 ). In VnAc2601 the same two parameters, $\lambda$ and $\delta$, were doubled using a factor of 2.1782 (Table 5, Column 3).

The acetate-dependent part of the equations for NADH and NADPH serves as the 'substrate throttle'. The cell-protein (biomass)-dependent part of these equations serves as a base-line. To calculate this second part, we assumed the pyridine nucleotide ratio to cell-protein to be the same in these acetate-based cultures as it was in the pyruvate-based ones of Packard et al. (1996a). In this way we were able to keep the same parameters $\omega$ and $\eta$ (Eqs. (8) and (9)) as previously used (Table 5).

The optimization of the parameters was done assuming the decrease of the ETS-substrates, NADH and NADPH, occurs in parallel as was predicted in Packard et al. (1996a). Hence, one can use the same factor to correct simultaneously both substrate-throttle parameters, $\lambda$ and $\delta$. Consequently, a loop that searched for the optimum correction factor was computed by calculating the NADH and NADPH time-courses that best predicted the 
oxygen consumption during the experiment. This technique estimated the output respiration from the EKM (Eq. (6)) by looking for the parameter that provides a linear regression model with a slope close to 1 . It used the smoothed time-profile of $R_{O_{2}}$ as the standard. This technique forced the model towards the most realistic prediction as possible. The reliability of the parameters found for the marine bacterium Vibrio natriegens was judged on two criteria. First, their ability to generate declining time profiles of NADH and NADPH within a biologically reasonable range (White et al., 1964; Lehninger, 1970; Walsh and Koshland Jr., 1984; Lehninger et al., 1993) as the acetate diminished in the culture media. Second, their ability to provide realistic respiration output data throughout the time-course of the experiment. For the kinetic constants $\left(K_{i a}, K_{N A D H}\right.$ and $K_{N A D P H}$ in Table 2) we used those from Experiment B in Packard et al. (1996a).

\section{Results and Discussion}

Fig. (1) shows time-courses of the culture biomass (cell-protein), carbon source (acetate), potential respiration (the in vitro ETS, $\left.A_{E T S}\right)$ and measured respiration for one experiment with $P$. nautica and two experiments with $V$. natriegens. In the beginning the cultures grew exponentially on the acetate; they passed through a short stationary phase; and then, as the acetate was exhausted, they fell into a senescent state. The experiments used this transition between exponential growth and senescence to separate the enzymatic capacity for respiration, the ETS activity, from the physiological expression of this capacity, the measured oxygen consumption. This strategy enabled us to challenge the predictive capability of the two models. It facilitated 
the comparison of the EKM's output to the MTE's output during realistic biological conditions. During the exponential growth phase, prediction from either ETS activity or cell protein is not a challenge because respiration, ETS activity and cell-protein trend in parallel. However, during senescence cell-protein and ETS activity trend together, but respiration breaks away and decreases rapidly. Thus in senescent phase predicting respiration from either cell-protein or ETS activity requires causal-level understanding of the respiratory mechanism.

Acetate was consumed rapidly as the respiration, ETS activity, and cellprotein increased. All cultures behaved similarly (Fig. 1). Shortly after the acetate was exhausted the respiration declined to very low levels even though the ETS activity and the bacterial biomass remained high. In this situation, with the carbon source exhausted, the respiration appears uncoupled from both the biomass and the ETS activity. In effect, within 7 hours the ratio of both the respiration to cell-protein and the ratio of respiration to ETS activity decreased to 0.2 and 0.25 of their value during exponential phase. This can explain some of the error in respiration inherent in both Kleiber's law and the R/ETS ratio used in oceanographic research. What is the cause of this apparent uncoupling if the ETS is the causal basis of respiration? The parallelism in the declining acetate and declining respiration rate (Fig. 1) provides a clue. If the substrates for the electron transport complexes fall as does the acetate, then the activity of these enzyme complexes would be throttled down the way the reaction rate in an enzyme-catalyzed reaction is modulated by substrate levels in a Michaelis-Menten equation (Fig. 2). Here, these substrate declines were modelled from the acetate declines in the three 
experiments (Fig. 1) using Eqs. (8) and (9). At this point it must be remembered that the ETS activity measured at any time in the bacteria cultures, whether the cells are in exponential or in senescent growth, is the activity measured in the presence of unlimited substrates. This condition forces the ETS complexes to react with NADH and NADPH at the complexes' maximum capacity regardless of how fast they were reacting in the living, intact bacteria cell. Thus ETS in Eq. (6) is equivalent to a Michaelis-Menten $V_{\max }$ as we have said in the Introduction.

We emphasize that the EKM is based on the observation that bacterial respiration declines in parallel with declining concentrations of carbon source (acetate) in the culture medium suggesting that natural ETS substrates would also decline in parallel with the carbon source. Accordingly a rectangular hyperbola from the Michaelis-Menten expression, describing a declining reaction rate as a function of falling substrate, explains the decrease in the in vivo ETS activity and hence the whole-cell respiration rate. Note here, that the in vivo ETS activity is the unmeasured ETS activity in the cell, not the ETS activity measured in a test tube. This later ETS activity (in vitro) is the Michaelis-Menten $V_{\max }$ discussed above. The former ETS activity in the cell is equivalent to the whole-cell respiration rate. Our entire effort is an attempt to create a conceptual and mathematical bridge between the later and the former ETS activities. This approach, as embodied in our previous model (Packard et al., 1996a), successfully predicted respiration in pyruvate-based cultures of Ps. nautica. Here, the same model predicts the respiration in acetate-based cultures of both $P$. nautica and $V$. natriegens (Fig. 3). The three respiration predictions from the original model are good, 
especially for P. nautica (Fig. 4, Panel A), but because the predictions for $V$. natriegens (Fig. 4, Panels B and C) were not optimum, parameters $\lambda$ and $\delta$ were modified again to produce the new pyridine nucleotide profiles in Fig. 5 (Panels A and B) and new respiration predictions. These new respiration predictions, as well as a replot of the original respiration prediction for the experiment with P. nautica are shown in Panel A of Figs. 6, 7 and 8. They do improve the prediction of respiration in experiments with $V$. natriegens. It now falls on future laboratory measurements of the actual $\mathrm{NADH}$ and NADPH time courses to verify both the concept of the EKM and the parameters $\lambda$ and $\delta$.

In order to show the predictive capacity of the two respiration models (EKM and MTE) in the different physiological phases of bacterial growth, the modelled respiration and measured respiration are compared in Panels AB and C-D, respectively, of Figs. 6, 7 and 8. These plots consider all the data from the beginning of the three cultures to their ends, so all physiological states are considered. The coefficients of determination, $\mathrm{r}^{2}$ values, for the EKM are all above 0.94 while for the MTE they would be meaningless and so they were not calculated. In effect, the respiration time-courses predicted by the MTE in Panel $\mathrm{C}$ of Figs. 6, 7 and 8 completely misrepresent the measured respiration time-course during steady state and nutrient limitation conditions. The MTE only models respiration well during the exponential growth phase. In contrast, the EKM predicts the respiration all through the different phases of bacterial growth. 


\section{Conclusions}

Respiratory oxygen consumption in two species of marine bacteria, during exponential growth, steady state and nutrient-limited stationary phases, can be modelled from measurements of the in vitro respiratory electron transport system activity (ETS), the cell protein, the carbon source (acetate). The model's algorithm is based on Michaelis-Menten substrate kinetics. If the predicted NADH and NADPH time courses are verified, future respiration calculations will be made solely from measurements of ETS activity, [NADH] and $[\mathrm{NADPH}]$ via Eq. (6).

This Enzyme Kinetic Model, besides having a better mechanistic basis, describes respiration better than does the Metabolic Theory of Ecology model under conditions of nutrient-limitation.

We argue that respiration modeling could be improved by recognizing that the respiratory electron transport system, and not biomass, is the causal base of respiration, that the ETS is regulated by the availability of reduced pyridine nucleotides, and that it responds to temperature changes via the impact of temperature on the Arrhenius energy of activation as described by the Arrhenius equation.

The model we propose is expressed as:

$$
R_{1}=\frac{E T S_{0}[S] e^{\frac{-E_{a}}{R_{g}\left(T_{1}-T_{0}\right)}}}{K+[S]}
$$

where $R_{1}$ is the respiration rate measured at $T_{1}, E T S_{0}$ is the potential respiration rate (the Michaelis-Menten $V_{\max }$ of the ETS), measured at another temperature $\left(T_{0}\right), K$ is a bisubstrate kinetics expression analogous to the Michaelis-Menten $K_{m}$, and S represents the substrates (see Introduction). 
In this model when $T_{0}=T_{1}$ the model equation reduces to:

$$
R_{0}=\frac{E T S_{0}[S]}{K+[S]}
$$

Acknowledgements. The authors wish to thank Prof. J.-P. Gagné from the University of Québec at Rimouski for his analysis of the acetate in the bacteria cultures and to Ms. L. St-Amand and B. Lagacé for their assistance with the culture maintenance and the biochemical analysis. The authors are also grateful to P. Jiménez-Amat from the Institut de Ciències del Mar in Barcelona (ICM-CSIC) and P. Llucià-Roura for comments and discussion. Financial support was provided by the University of Las Palmas de Gran Canaria (ULPGC), the Spanish Ministry of Education and Science, the Graduate Program in Oceanography at the ULPGC, ICM-CSIC, and the research grants MODIVUS (CTM2005-04795/MAR), EXOME (CTM 2008-01616), and OITHONA (CTM200760052). T. Packard was supported by contract EXMAR SE-539 10/17 (Proyecto Estructurante en Ciencias Marinas). This is contribution \#200906 from the Bigelow Laboratory for Ocean Sciences. 


\section{References}

Allen, A. P., Gillooly, J. F., 2007. The mechanistic basis of the metabolic theory of ecology. Oikos 116, 1073-1077.

Arrhenius, S., 1889. Über die Reaktionsgeschwindigkeit bei der Inversion von Rohrzucker durch Säuren. Zeitschrift für Physikalische Chemie Stöchiometrie und Verwandtschaftslehre 4 (2), 226-248.

Arrhenius, S., 1915. Quantitative Laws in Biological Chemistry. Bell and Son, London.

Baumann, P., Baumann, L., 1981. The prokaryotes: a handbook on the biology of bacteria: ecophysiology, isolation, identification, applications. Springer-Verlag, New York, Ch. The marine Gram-negative eubacteria: genus Photobacterium, Beneckea, Alteromonas, Pseudomonas and Alcaligenes, pp. 1302-1330.

Brown, J. H., Gillooly, J. F., Allen, A. P., Savage, V. M., West, G. B., 2004. Toward a Metabolic Theory of Ecology. Ecology 85, 1771-1789.

Brown, J. H., West, G. B., 2000. Scaling in Biology. Oxford University Press, USA.

Brown, J. H., West, G. B., Enquist, B. J., 2000. Scaling in Biology: Patterns and processes, causes and consequences.

Enquist, B. J., Brown, J. H., West, G. B., 1998. Allometric scaling of plant energetics and population density. Nature 395, 163-165.

Enquist, B. J., West, G. B., Brown, J. H., 2000. Scaling in Biology. Oxford University Press., Oxford, Ch. Quarter-power allometric scaling in vascular plants: functional basis and ecological consequences, pp. 167-198.

Farquhar, G. D., von Caemmerer, S., Berry, J. A., 1980. A biochemical model of photosynthetic $\mathrm{CO}_{2}$ assimilation in leaves of C3 species. Planta 149, 78-90.

Feynman, R. P., 1998. Six not-so-easy pieces: Einstein's relativity, symmetry, and spacetime. Perseus, 152 pp. 
Gillooly, J. F., Allen, A. P., Savage, V. M., West, G. B., Brown., J. H., 2006. Response to Clarke and Fraser: effects of temperature on metabolic rate. Funct. Ecol. 20, 400-404.

Gillooly, J. F., Brown, J. H., West, G. B., Savage, V. M., Charnov, E. L., 2001. Effects of size and temperature on metabolic rate. Science 293, 2248-2251.

Gillooly, J. F., Charnov, E. L., Brown, J. H., Savage, V. M., West, G. B., 2003. How Reliable is the Biological Time Clock? Brief Communication. Nature 424, 270.

Gillooly, J. F., Charnov, E. L., West, G. B., Savage, V. M., Brown, J. H., 2002. Effects of size and temperature on developmental time. Nature 417, 70-73.

Hochachka, P. W., Somero, G. N., 2002. Biochemical Adaptation. Mechanism and Process in Physiological Evolution. Oxford University Press, New York.

Hutcheson, M., 1995. Trimmed resistant weighted scatterplot smooth. Ph.D. thesis, Cornell University.

King, G. M., Berman, T., 1984. Potential effects of isotope dilution on apparent respiration in ${ }^{14} \mathrm{C}$ heterotrophy experiments. Mar. Ecol. Prog. Ser. 19, 175-180.

Kleiber, M., 1932. Body size and metabolism. Hilgardia 6, 315-332.

Kleiber, M., 1961. The Fire of Life: An Introduction to Animal Energetics. John Wiley \& Sons.

Lehninger, A. L., 1970. Biochemistry: The Molecular Basis of Cell Structure and Function, 1st Edition. Worth Publishers, New York.

Lehninger, A. L., Nelson, D. L., Cox, M. M., 1993. Principles of Biochemistry. Worth Publishers, New York.

Lowry, O. H., Rosebrough, N. J., Farr, A. L., Randall, R. J., 1951. Protein measurement with the Folin Phenol Reagent. J. Biol. Chem. 193, 265-275. 
Nissen, H., Heldal, M., Norland, S., 1987. Growth, elemental composition and formation of polyphosphate bodies in Vibro natriegens cultures shifted from phosphate-limited to phosphate-pulsed media. Can. J. Microbiol. 33, 583-588.

Niven, D. F., Collins, P. A., Knowles, C. J., 1977. Adenylate energy charge during batch cultures of Beneckea natriegens. J. Gen. Microbiol. 98, 95-108.

Packard, T. T., Berdalet, E., Blasco, D., Roy, S., Amand, L. S., Legacé, B., Lee, K., Gagné, J. P., 1996a. Oxygen consumption in the marine bacterium, Pseudomonas nautica predicted from ETS activity and bisubstrate kinetics. J. Plankton Res. 18 (10), 1819-1835.

Packard, T. T., Berdalet, E., Roy, S., Blasco, D., Lee, K., Gagné, J. P., 1996b. $\mathrm{CO}_{2}$ production predicted from Isocitrate dehydrogenase activity and bisubstrate enzyme kinetics in the marine bacterium, Pseudomonas nautica. Aquat. Mar. Ecol. 11, 11-19.

Packard, T. T., Blasco, D., Estrada, M., 2004. Modeling physiological processes in plankton on enzyme kinetic principles. Sci. Mar. 68 (1), 49-56.

Packard, T. T., Christensen, J. P., 2004. Respiration and vertical carbon flux in the Gulf of Maine water column. J. Mar. Res. 62 (1), 93-115.

Packard, T. T., Gómez, M., 2008. Exploring a first-principles-based model for zooplankton respiration. ICES J. Mar. Sci. 65 (3), 371-378.

Packard, T. T., Healy, M. L., Richards, F. A., 1971. Vertical distribution of the activity of the respiratory electron transport system in marine plankton. Limnol. Oceanogr. 16, $60-70$.

Packard, T. T., Williams, P. L. B., 1981. Rates of respiratory oxygen consumption and electron transport in surface seawater from the northwest Atlantic Ocean. Oceanolog. Acta 4, 351-358. 
Roy, S. O., Packard, T. T., 2001. $\mathrm{CO}_{2}$ production rate predicted from isocitrate dehydrogenase activity, intracellular substrate concentrations and kinetic constants in the marine bacterium, Pseudomonas nautica. Mar. Biol. 138 (6), 1251-1258.

Segel, I. H., 1993. Enzyme Kinetics: Behavior and Analysis of Rapid Equilibrium and Steady-State Enzyme Systems. Wiley Classics Library. Wiley-Interscience. New York.

Walsh, K., Koshland Jr., D. E., 1984. Determination of flux through the branch point of two metabolic cycles. The tricarboxylic acid cycle and the glyoxylate shunt. J. Biol. Chem. 259, 9646-9654.

Weibel, E. R., 2002. The pitfalls of power laws. Nature 417 (6885), 131-132.

West, G. B., Brown, J. H., Enquist, B. J., 1997. A general model for the origin of allometric scaling laws in biology. Science 276, 122-126.

West, G. B., Brown, J. H., Enquist, B. J., 2000. The origin of universal scaling laws in biology. Scaling in Biology. Oxford University Press, Oxford.

West, G. B., Brown, J. H., Enquist, B. J., 2001. A general model for ontogenetic growth. Nature 413, 628-631.

White, A., Handler, P., Smith, E. L., 1964. Principles of Biochemistry, 3rd Edition. McGraw-Hill, New york.

Whitfield, J., 2005. Biogeography: Is everything everywhere? Science 310, 960-961.

Whitfield, J., 2006. In the beat of a heart: Life, Energy, and the unity of Nature. Joseph Henry Press. 


\section{List of Captions (Tables and Figures)}

Table 1. Pseudomonas nautica. Data from Experiment A (PnAc290693). Mid-Acetate and Mid-Protein are the time-averaged values of acetate $(P)$ and cell protein $(M)$ over the previous sampling period. These mid-points are used to model the intracellular NADP and NADPH time profiles for Eqs. (8) and (9). ${ }^{*}$ The acetate beyond the lowest value $(0,82)$ increased slowly to a value of 2,04 , but for analytical reasons was considered unreliable. Consequently for modeling we assigned a value of 0,01 .

Table 2. Vibrio natriegens. Data from Experiment B (VnAc110593). Mid-Acetate and Mid-Protein are the time-averaged values of acetate $(P)$ and cell protein $(M)$ over the previous sampling period. These mid-points are used to model the intracellular NADP and NADPH time profiles for Eqs. (8) and (9). ${ }^{*}$ The acetate beyond the lowest value (0) was not detectable, for modeling we assigned a value of 0,01 .

Table 3. Vibrio natriegens. Data from Experiment C (VnAc260193). Mid-Acetate and Mid-Protein are the time-averaged values of acetate $(P)$ and cell protein $(M)$ over the previous sampling period. These mid-points are used to model the intracellular NADP and NADPH time profiles for Eqs. (8) and (9). ${ }^{*}$ The acetate beyond the lowest value (0) was not detectable, for modeling we assigned a value of 0,01 .

Table 4. Summary of equations used in the Enzyme Kinetic Model (EKM).

Table 5. Kinetic constants and parameters that were used to model (EKM) the intracellular NADH and NADPH concentrations from Eqs. (8) and (9) and to predict the respiration rate from Eqs. (6) and (7). The units for the kinetic constants are $\mu M$. The units for the parameters are as follows: $\lambda, \mu m o l$ NADPH (mmol pyruvate) ${ }^{-1} ; \eta, \mu m o l$ NADPH (mg protein $)^{-1} ; \delta, \mu m o l$ NADH (mmol pyruvate) ${ }^{-1}$; and $\omega, \mu m o l$ NADPH (mg protein $)^{-1}$.Column 1 lists kinetic constants and parameters used in Experiment B of Packard et al. (1996a) and in all three experiments of this work. All the values of $\lambda$ and $\delta$ 
606 used in this work are numerically the same as in Packard et al. (1996a) but for acetate. The 607 results of their used are shown in Fig. 2. Column 2 and Column 3 list kinetic constants 608 and parameters (revised $\lambda$ and $\delta$ ) used for Experiment B and Experiment C, respectively, 609 in this work. The results of their use are shown in Fig. 5. Parameters in Column 2 and 3 610 have been changed as described in the text.

611 
Figure 1: Original data (symbols) and interpreted (Loess method (Hutcheson, 1995)) timecourse data (lines) for three experiments with two species of marine bacteria growing in acetate-based batch cultures. Panel A: Pseudomonas nautica in Experiment A showing observations of ETS activity (in vitro), $R_{O_{2}}$, protein and acetate over $27 \mathrm{~h}$. Panel B: Vibrio natriegens in Experiment B showing the same observations as in Panel A (same legend) but over 34h. Panel C: Vibrio natriegens in Experiment $\mathrm{C}$ as in Panel A and B but for 500h.The physiological state of the cells shifts between hours 10 and 20 from a well-nourished condition to a nutrient-limited condition. Analytical errors are given in Material and Methods.

Figure 2: Simulated time-courses for intracellular NADH and NADPH as calculated from (Eqs. (8) and (9)) for each of the three experiments. Panel A: Pseudomonas nautica in Experiment A. Panel B: Vibrio natriegens in Experiment B. Panel C: Vibrio natriegens in Experiment C. These time-courses used the kinetic constants and parameters listed in Table 5 (Column 1) and served as input in modeling the respiration in Fig. 3.

Figure 3: EKM modeling results using the original model from Packard et al. (1996a), but with acetate-based cultures instead of pyruvate-based ones. Panel A: Pseudomonas nautica. Experiment A showing the time-courses of measured respiration and in vitro ETS and compared to the modelled (EKM) respiration (from (Eq. (6)). Panel B: Vibrio natriegens. Experiment B as in Panel A. Panel C: Vibrio natriegens. Experiment C as in Panel A and B.

Figure 4: Comparing modelled (Fig. 3) and measured (Fig. 1) respiration in all three experiments. In the linear regression equations the slope indicates the accuracy of the model. The coefficient of determination ( $\mathrm{r}^{2}$ values) indicates the fidelity of the modelled respiration to the shape of the measured respiration. Panel A: Pseudomonas nautica. Experiment A. Panel B: Vibrio natriegens. Experiment B as in Panel A. Panel C: Vibrio natriegens. Experiment $\mathrm{C}$ as in Panel A and B. 
Figure 5: Simulated time-courses for intracellular NADH and NADPH, as before, but recalculated from (Eqs. (8) and (9)). Panel A: Vibrio natriegens in Experiment B. Panel B: Vibrio natriegens in Experiment C. These time-courses used the kinetic constants and revised parameters listed in Table 5 (Column 2 and Column 3) and served as input for the revised respiration models in Panel A of Figs. 7 and 8.

Figure 6: Pseudomonas nautica (Experiment A). Panel A: EKM modeling results as in Fig. 3 using the NADH and NADPH time courses shown in Panel B of Fig. 2. Panel B: Comparison between the measured and EKM modelled respiration shown in Panel A. Panel C: MTE modeling results based on measured cell-protein (M) and Eq. (11). Panel D: Comparison of measured and modelled respiration from the MTE.

Figure 7: Vibrio natriegens (Experiment B). Panel A: EKM modeling results as in Fig. 3, but using the NADH and NADPH time courses shown in Panel A of Fig. 5. Panel B: Comparison between the measured and EKM modelled respiration shown in Panel A. Panel C: MTE modeling results based on measured cell-protein (M) and Eq. (12). Panel D: Comparison of measured and modelled respiration from the MTE.

Figure 8: Vibrio natriegens (Experiment C). Panel A: EKM modeling results as in Fig. 3, but using the NADH and NADPH time courses shown in Panel B of Fig. 5. Panel B: Comparison between the measured and EKM modelled respiration shown in Panel A. Panel C: MTE modeling results based on measured cell-protein (M) for Vibrio natriegens in Experiment B and Eq. (12). Panel D: Comparison of measured and modelled respiration from the MTE. 


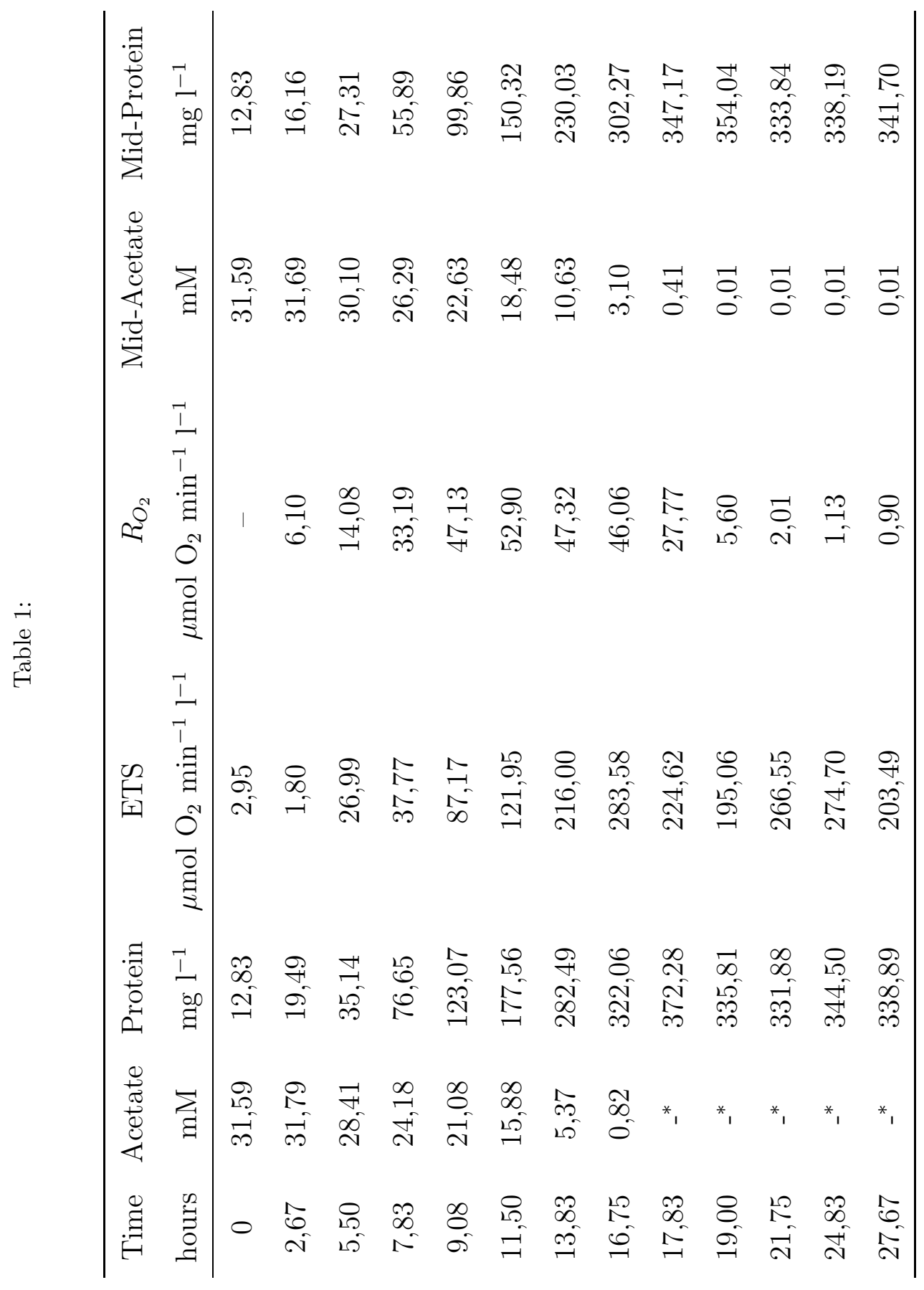




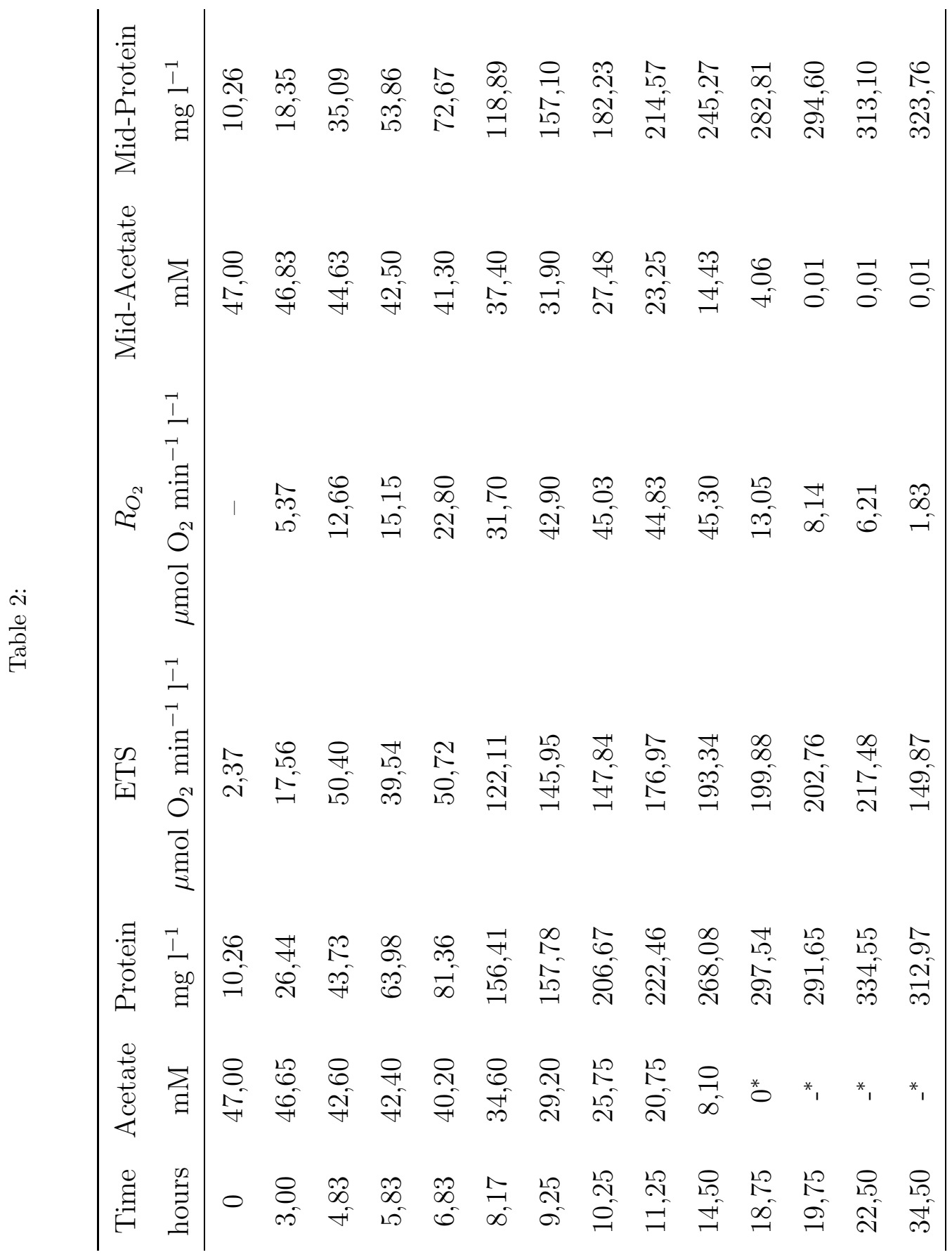




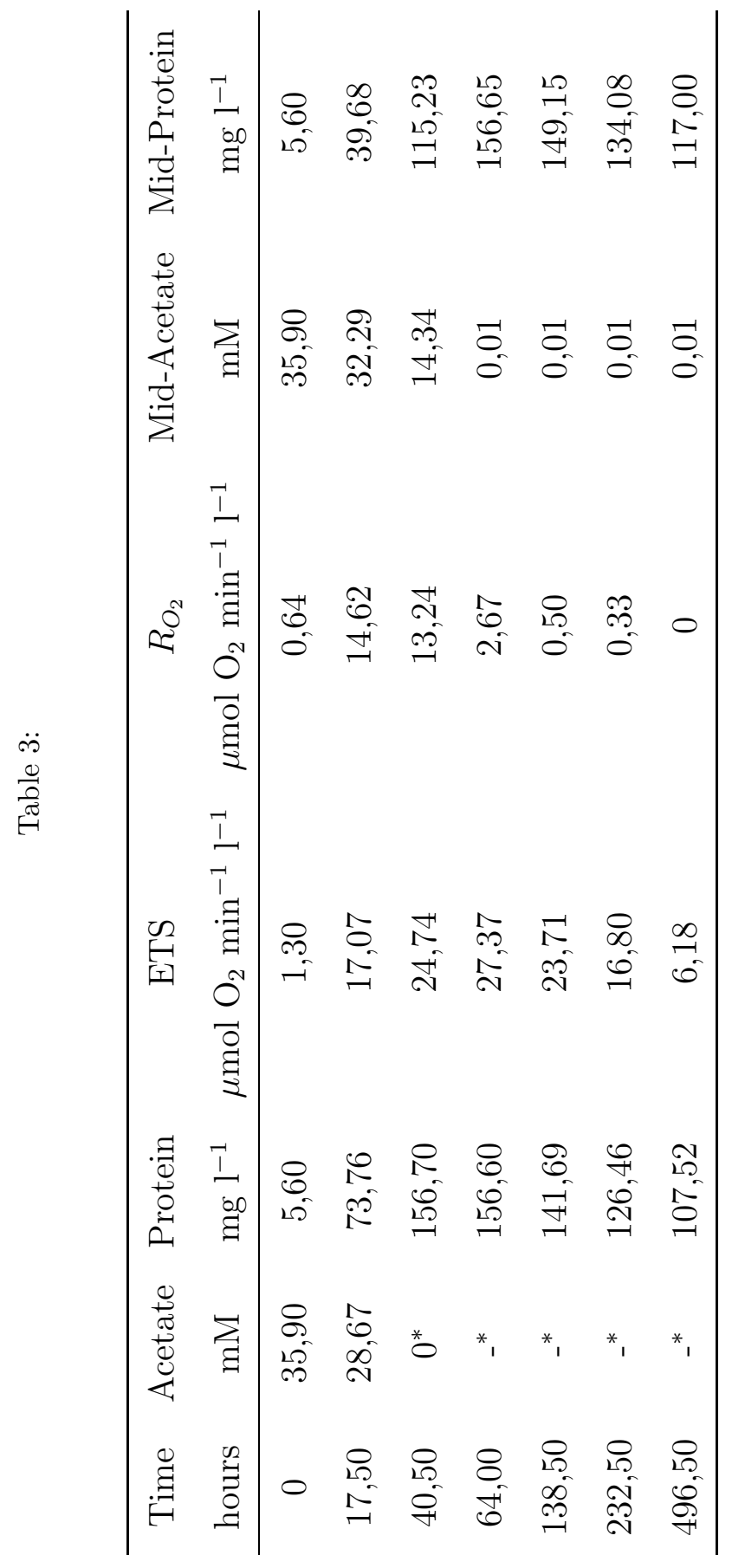


Table 4:

\begin{tabular}{ll}
\hline Eq. & $\mathrm{N}^{\circ}$ \\
\hline$R_{m}=E T S[\mathrm{NADH}][\mathrm{NADPH}] /\left(K_{\beta}+[\mathrm{NADH}][\mathrm{NADPH}]\right)$ & $(6)$ \\
$K_{\beta}=\left(K_{N A D H}\right)\left(K_{i a}\right)+\left(K_{N A D P H}\right)[\mathrm{NADH}]+\left(K_{N A D H}\right)[\mathrm{NADPH}]$ & $(7)$ \\
$\mathrm{NADH}=\delta P+\omega M$ & \\
$\mathrm{NADPH}=\lambda P+\eta M$ & $(9)$ \\
\hline
\end{tabular}




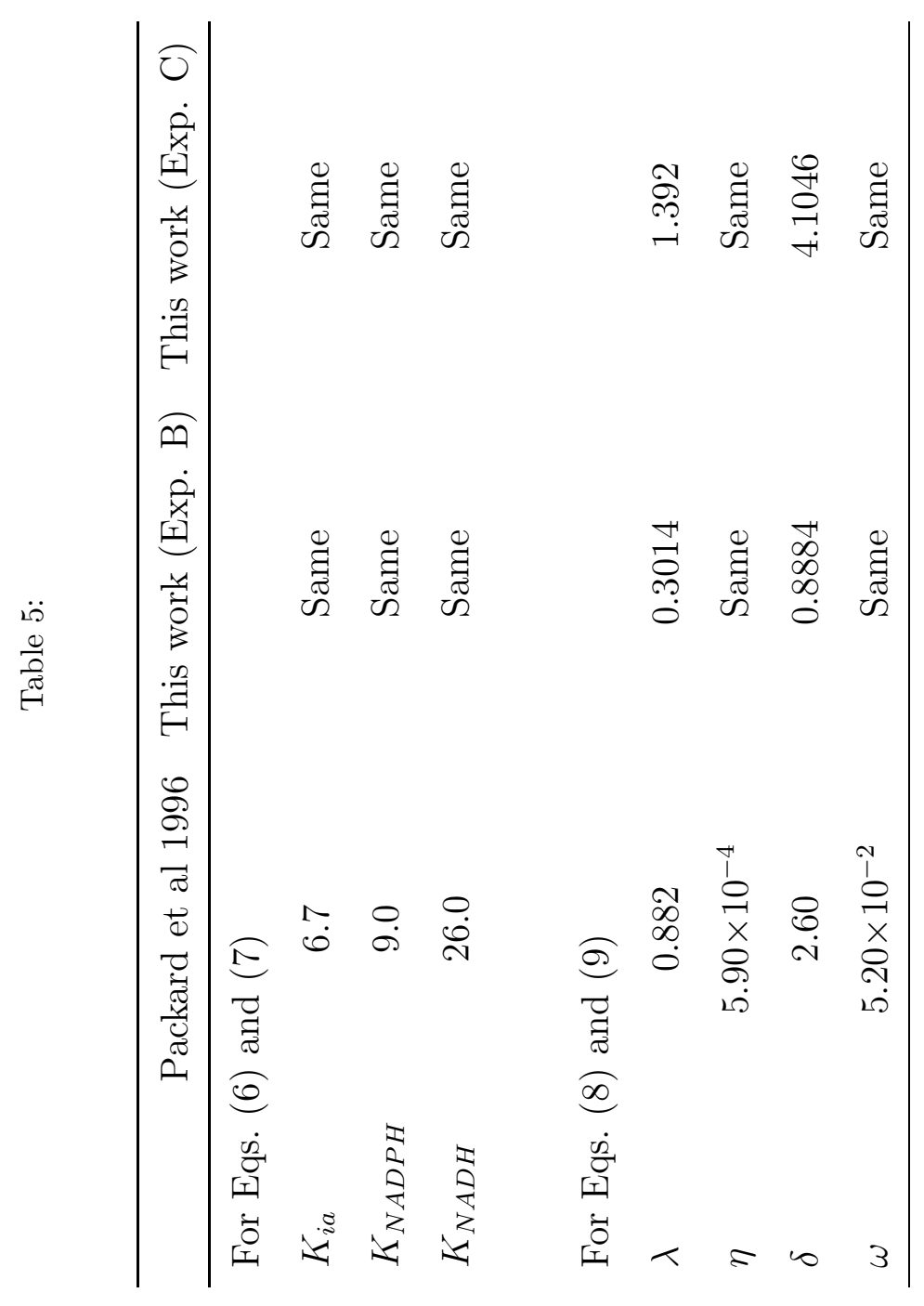


Figure
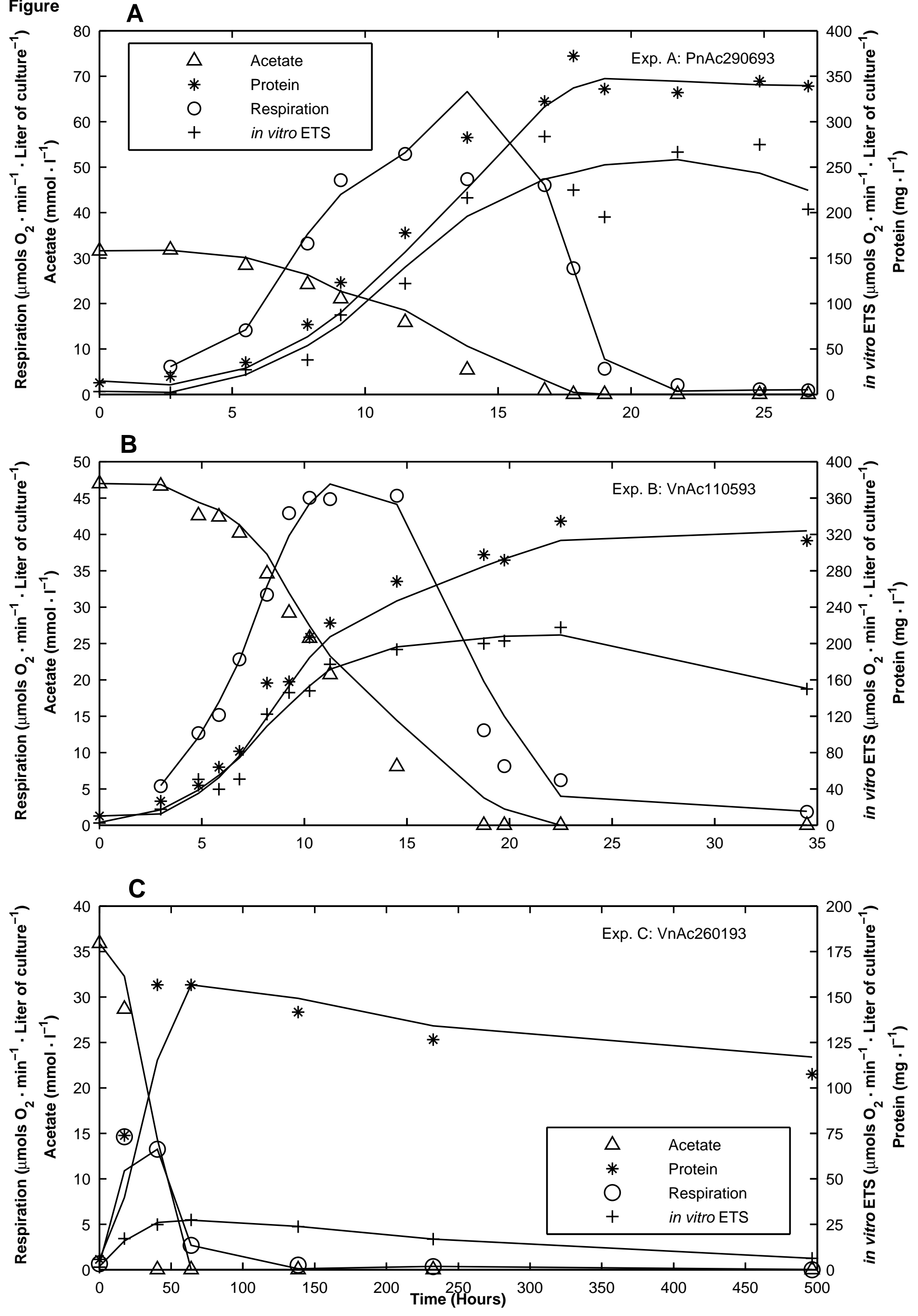


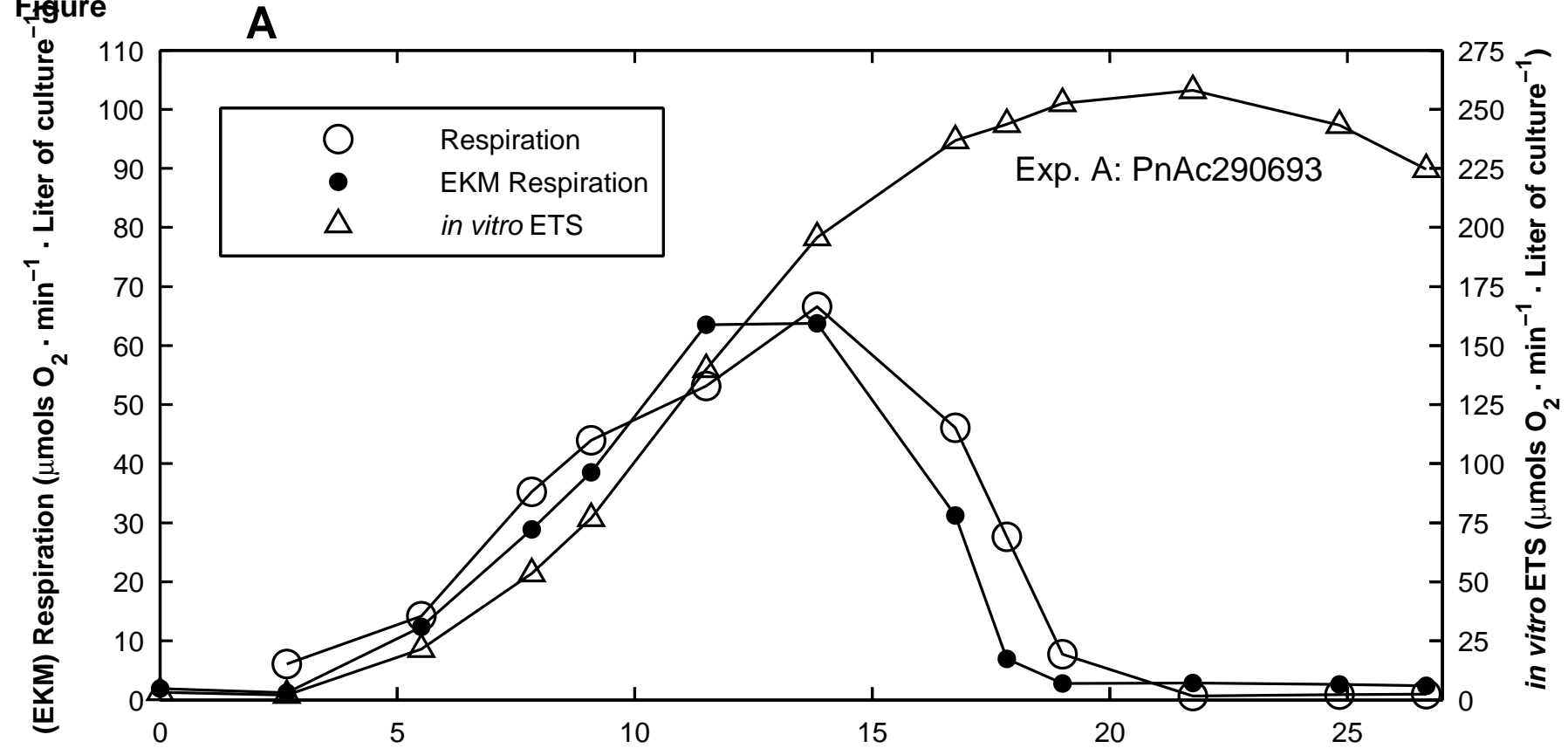

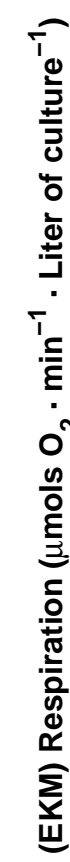

B

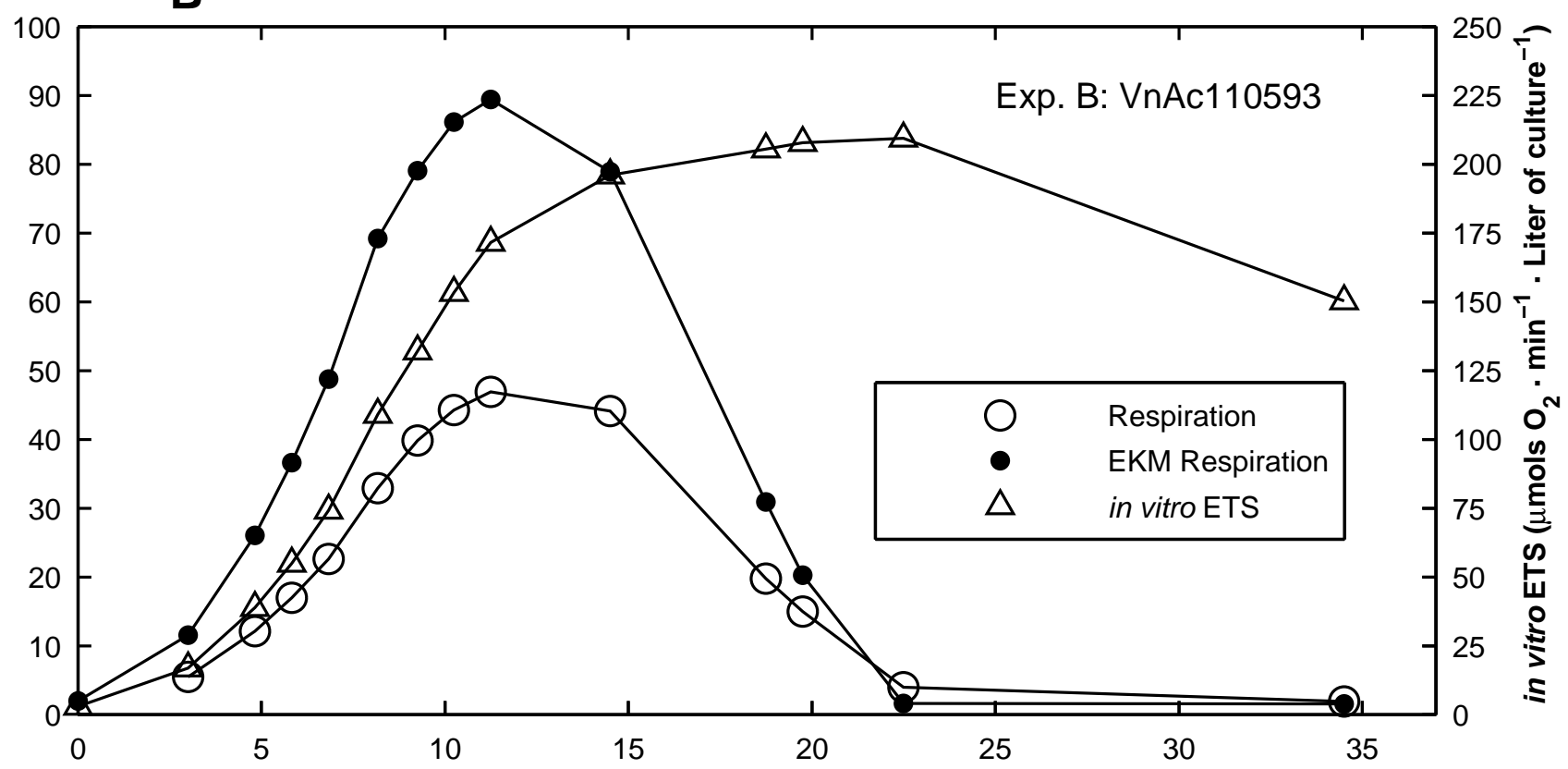

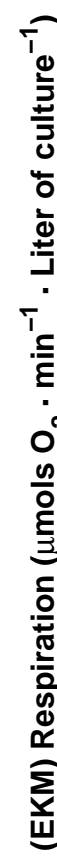

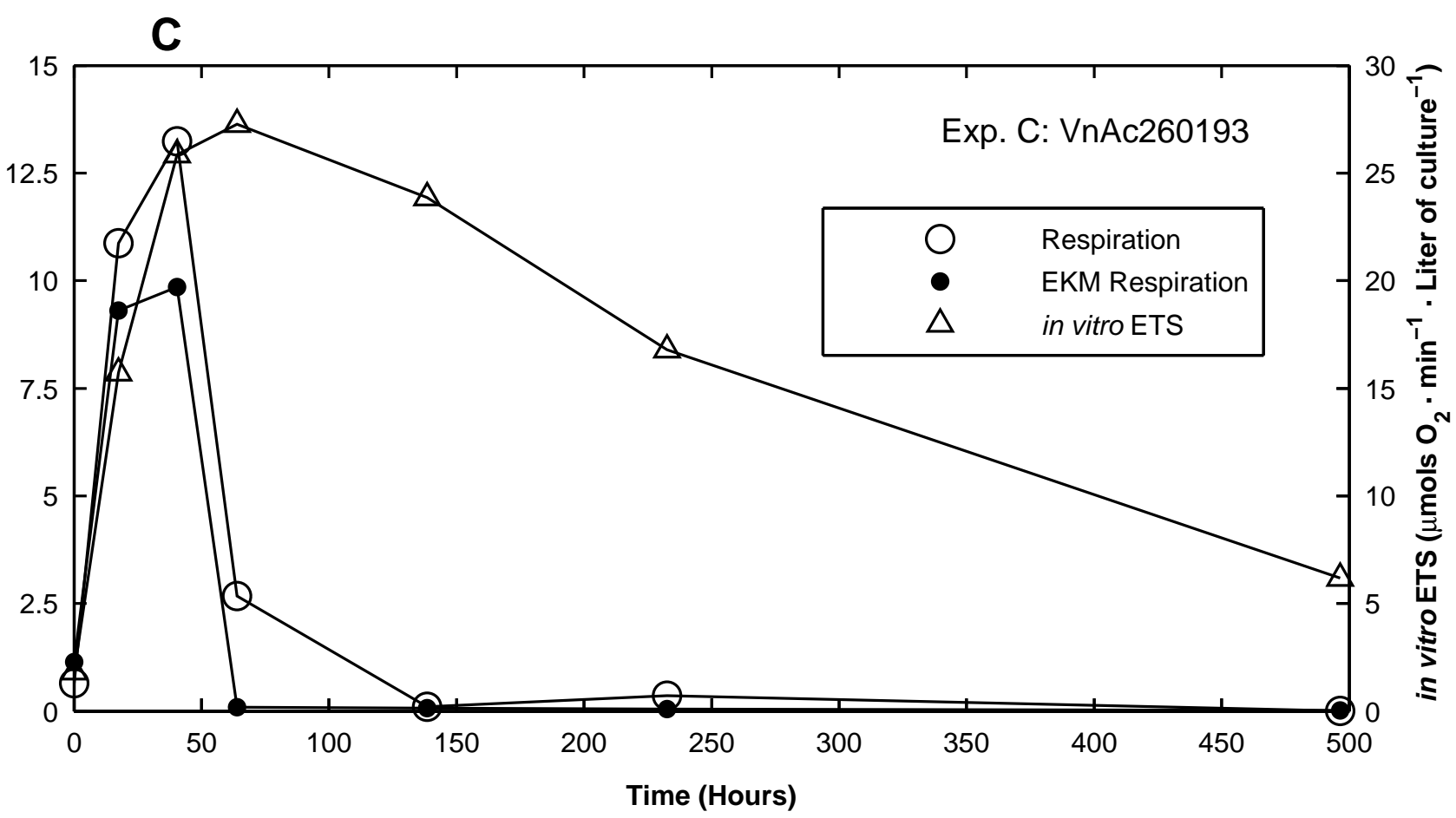




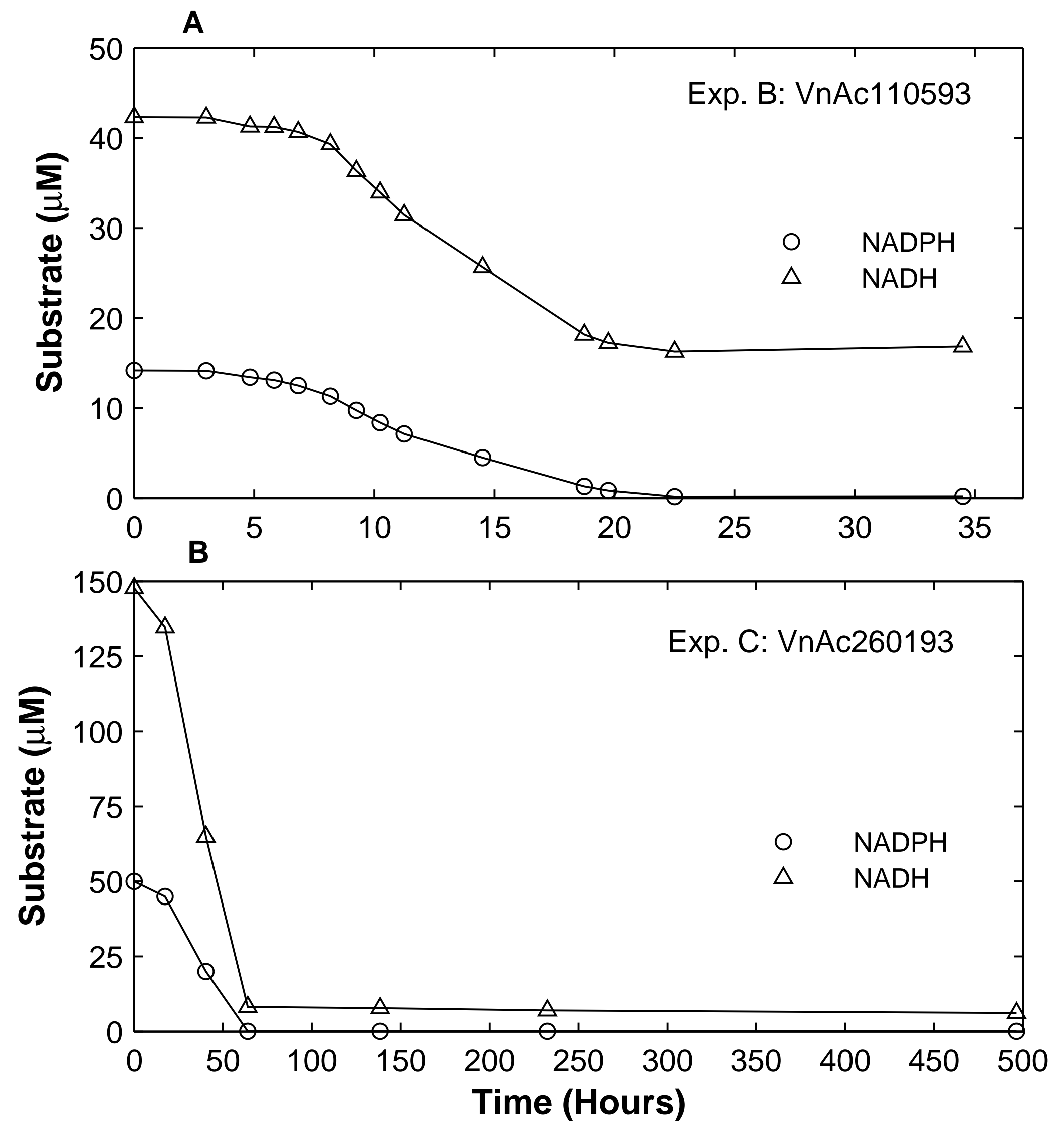



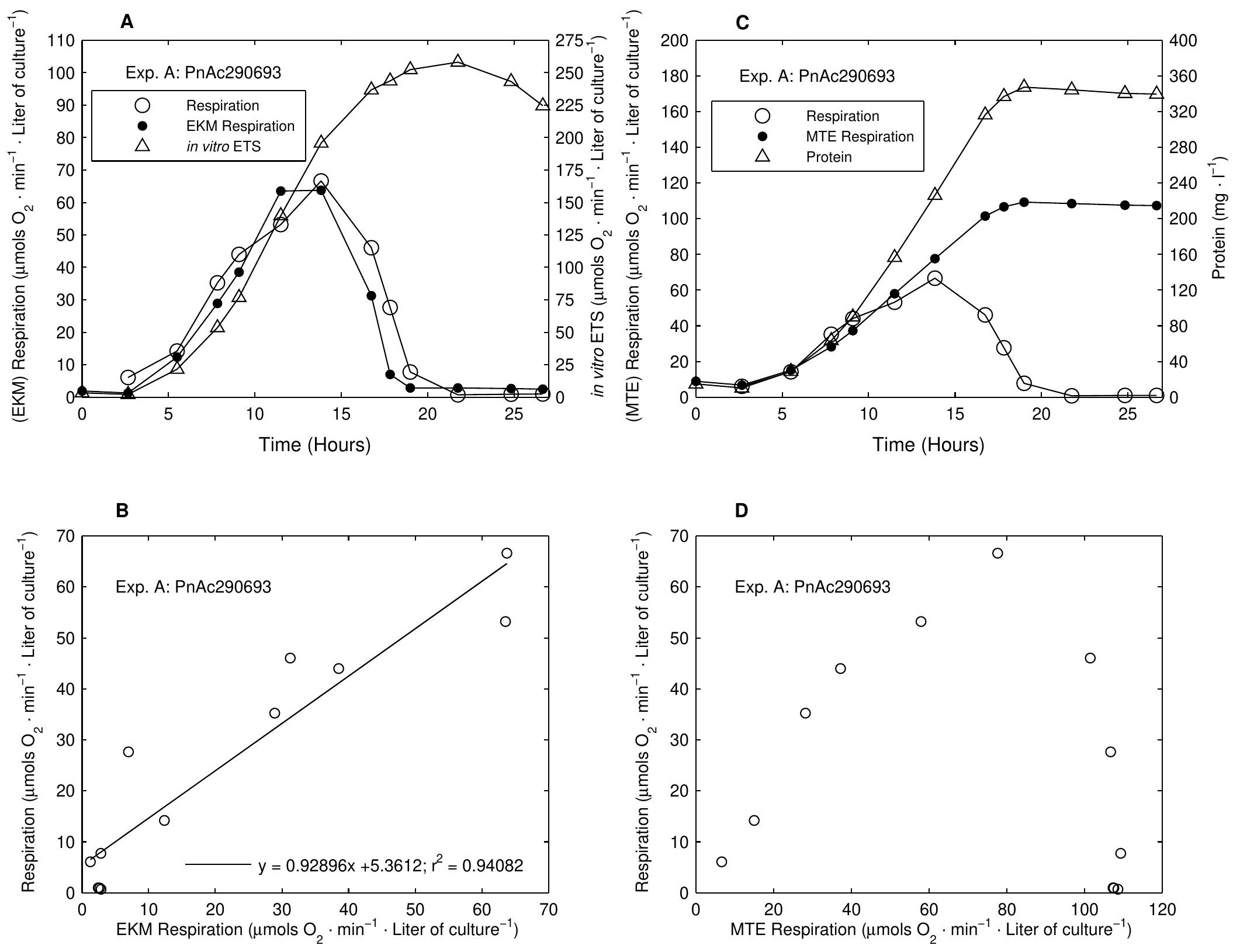
A

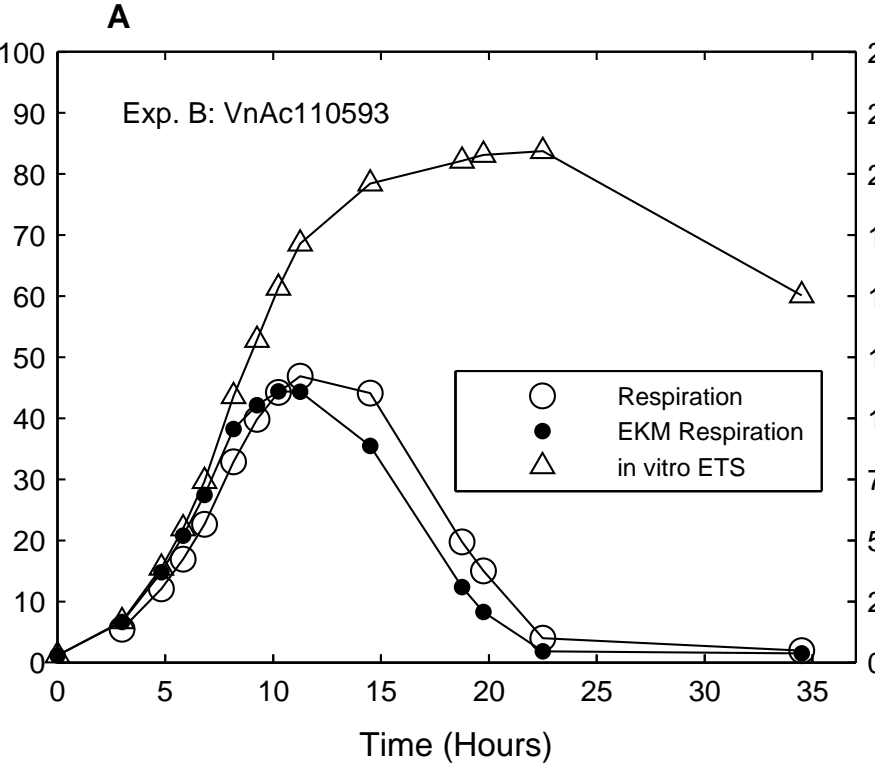

B

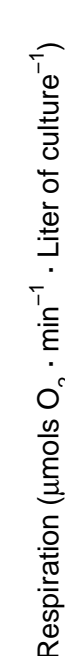

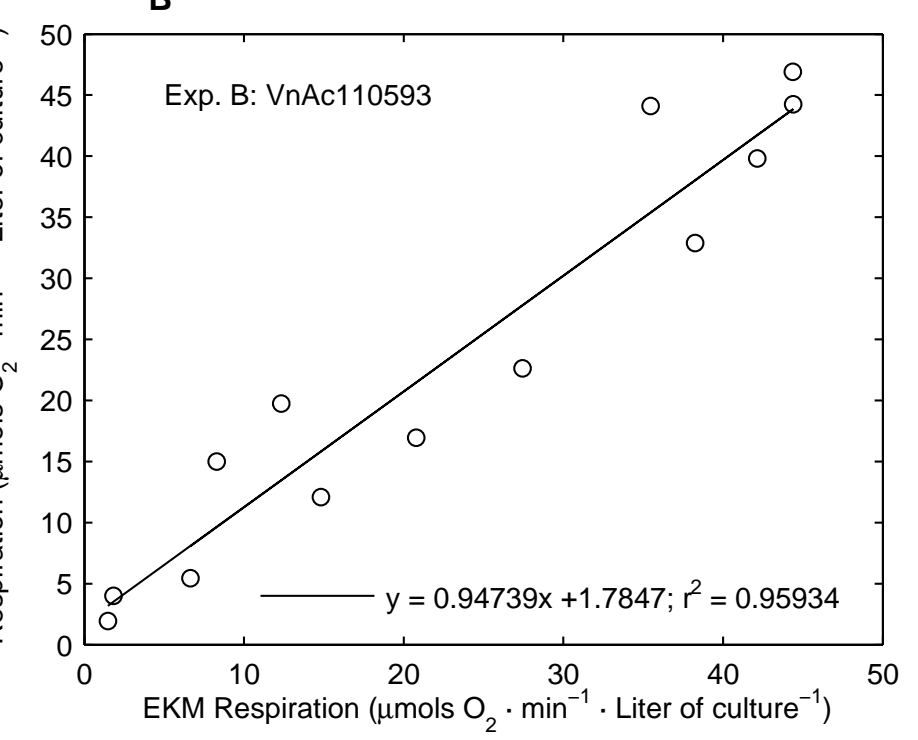

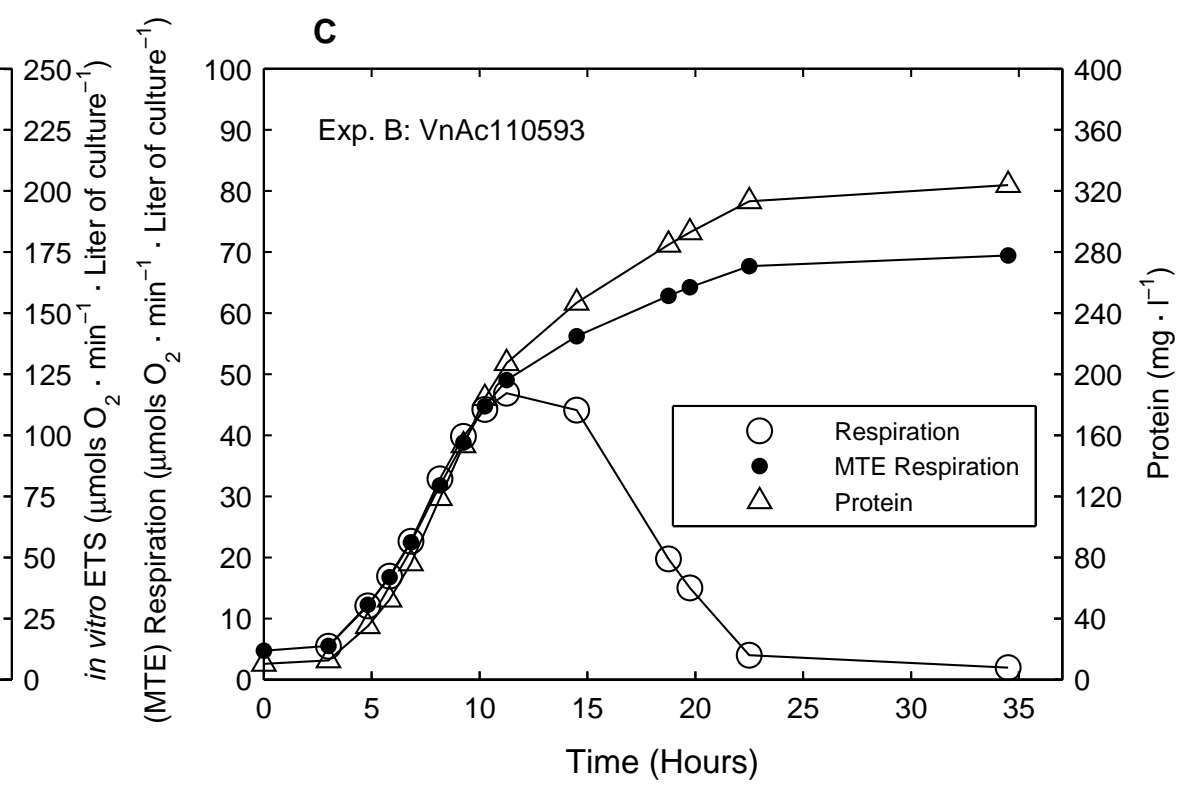

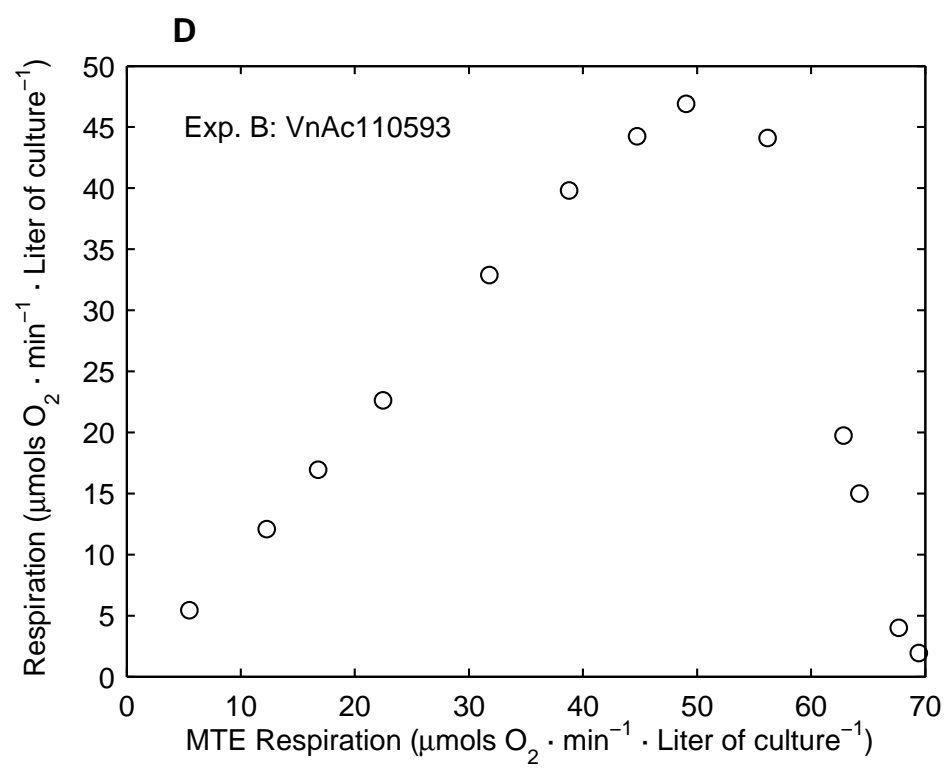



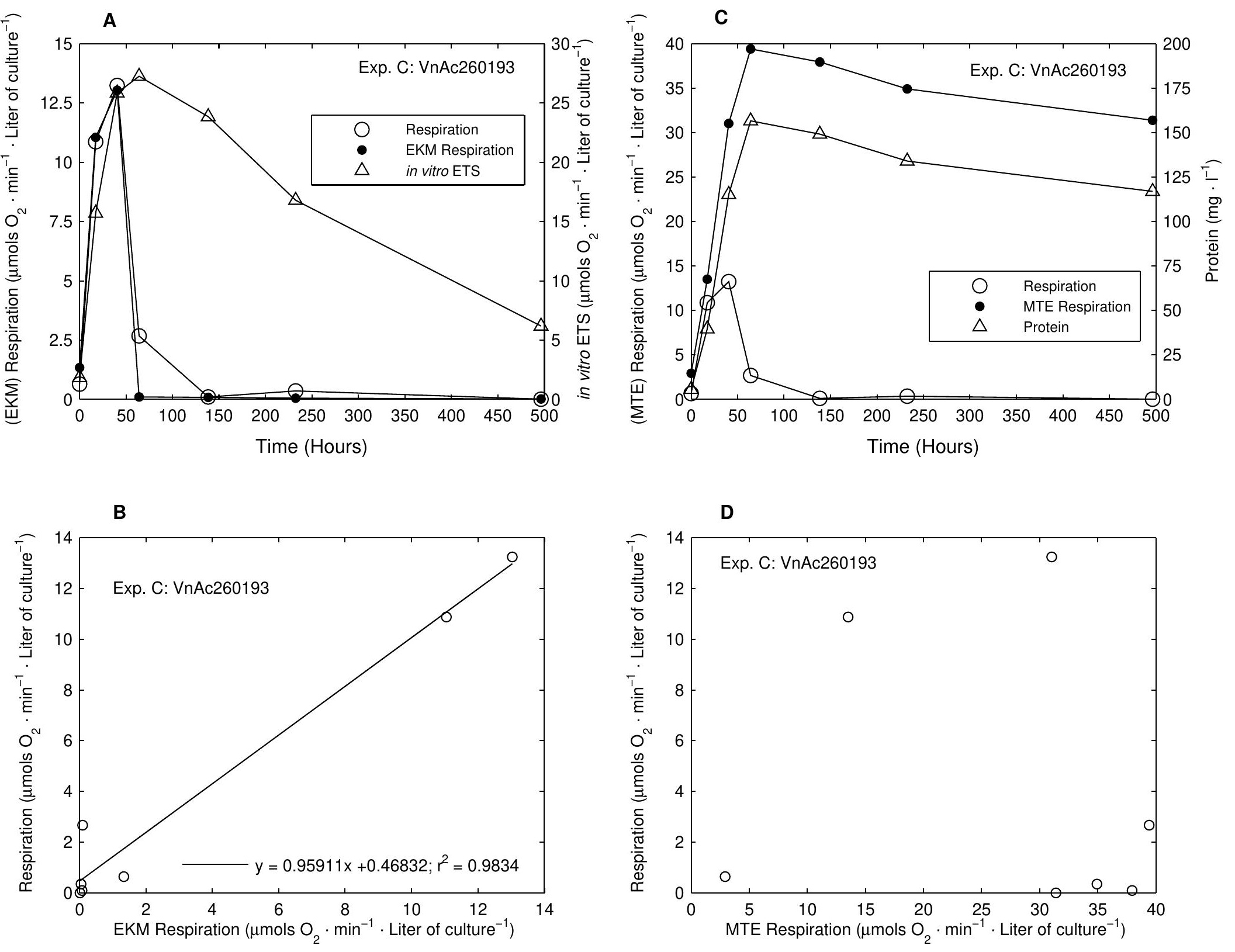